\title{
Resistance to chemotherapy is associated with altered glucose metabolism in acute myeloid leukemia
}

\author{
KUI SONG ${ }^{1,2^{*}}$, MIN LI $^{3 *}$, XIAOJUN XU ${ }^{2,4}$, LI XUAN $^{4}$, GUINIAN HUANG ${ }^{4}$ and QIFA LIU ${ }^{4}$ \\ ${ }^{1}$ Department of Hematology, The First Affiliated Hospital of Jishou University, Jishou, Hunan 416000; \\ ${ }^{2}$ Department of Hematology, Zhongshan City People's Hospital, Zhongshan, Guangdong 528400; ${ }^{3}$ Department of Pharmacy, \\ The First Affiliated Hospital of Jishou University, Jishou, Hunan 416000; ${ }^{4}$ Department of Hematology, \\ Nanfang Hospital of Southern Medical University, Guangzhou, Guangdong 510515, P.R. China
}

Received December 24, 2014; Accepted March 8, 2016

DOI: $10.3892 / \mathrm{ol} .2016 .4600$

\begin{abstract}
Altered glucose metabolism has been described as a cause of chemoresistance in multiple tumor types. The present study aimed to identify the expression profile of glucose metabolism in drug-resistant acute myeloid leukemia (AML) cells and provide potential strategies for the treatment of drug-resistant AML. Bone marrow and serum samples were obtained from patients with AML that were newly diagnosed or had relapsed. The messenger RNA expression of hypoxia inducible factor (HIF)-1 $\alpha$, glucose transporter (GLUT)1, and hexokinase-II was measured by quantitative polymerase chain reaction. The levels of $\mathrm{LDH}$ and $\beta$ subunit of human F1-F0 adenosine triphosphate synthase ( $\beta$-F1-ATPase) were detected by enzyme-linked immunosorbent and western blot assays. The HL-60 and HL-60/ADR cell lines were used to evaluate glycolytic activity and effect of glycolysis inhibition on cellular proliferation and apoptosis. Drug-resistant HL-60/ADR cells exhibited a significantly increased level of glycolysis compared with the drug-sensitive HL-60 cell line. The expression of HIF-1 $\alpha$, hexokinase-II, GLUT1 and LDH were increased in AML patients with no remission (NR), compared to healthy control individuals and patients with complete remission (CR) and partial remission. The expression of $\beta$-F1-ATPase in patients with NR was decreased compared with the expression in the CR group. Treatment of HL-60/ADR cells with 2-deoxy-D-glucose or 3-bromopyruvate increased in vitro sensitivity to Adriamycin (ADR), while treatment of HL-60 cells did not affect drug cytotoxicity. Subsequent to treatment
\end{abstract}

Correspondence to: Professor Qifa Liu, Department of Hematology, Nanfang Hospital of Southern Medical University, 1838 North Guangzhou Road, Guangzhou, Guangdong 510515, P.R. China

E-mail: zs_hematology@163.com

${ }^{*}$ Contributed equally

Key words: glycolysis, oxidative phosphorylation, chemoresistance, acute myeloid leukemia for $24 \mathrm{~h}$, apoptosis in these two cell lines showed no significant difference. However, glycolytic inhibitors in combination with ADR increased cellular necrosis. These findings indicate that increased glycolysis and low efficiency of oxidative phosphorylation may contribute to drug resistance. Targeting glycolysis is a viable strategy for modulating chemoresistance in AML.

\section{Introduction}

Acute myeloid leukemia (AML) is the most common type of leukemia in adults, and anthracycline-based chemotherapy is the principal option for the treatment of AML. Despite advances in AML treatment, $20 \%$ of AML patients do not respond to induction chemotherapy, and $40-60 \%$ of patients relapse (1). The majority of therapeutic failures are due to cellular resistance to anti-leukemic drugs (2). Therefore, it is important to identify strategies that reverse resistance to drugs.

The development of refractory AML remains unclear, and may involve various molecular mechanisms, including the altered expression of one or several multidrug resistance (MDR) genes, including multidrug resistance-associated protein 1 (MRP1), lung resistance related protein (LRP) and P-glycoprotein (P-gp) $(3,4)$. Previous studies have investigated altered glucose metabolism in chemoresistant leukemia cells (5-14). It has been reported that prednisolone resistance in patients with precursor B-cell acute lymphoblastic leukemia (ALL) was associated with an increased expression of genes involved in glucose metabolism $(5,6)$. Imatinib-resistant chronic myelogenous leukemia cells also exhibited a high glycolysis phenotype, with elevated glucose uptake and lactate production compared with imatinib-sensitive cells (7-10). In addition, AML cell lines with an increased level of glycolysis showed increased resistance to the induction of apoptosis in vitro due to a combination of all-trans retinoic acid and arsenic trioxide (11). Furthermore, inhibition of glycolysis by glycolytic inhibitors, such as 2-deoxy-D-glucose (2-DG), lonidamine (LND) and 3-bromopyruvate (3BrPA), or downregulation of the expression of glyceraldehyde-3-phosphate dehydrogenase (GAPDH) by RNA interference sensitizes prednisolone-resistant ALL cell lines to glucocorticoids (12). Acute leukemia subtypes, including pre-B-cell ALL, T-cell ALL and AML, demonstrated growth arrest and cell death 
when treated with the novel glycolysis inhibitor 3-BrOP. Potentiated adenosine triphosphate (ATP) depletion and pro-apoptotic effects were observed subsequent to treatment with 3-BrOP. Combined with the cytochrome $c$-reductase inhibitor antimycin A and the mammalian target of rapamycin (mTOR) inhibitor rapamycin, treatment with 3-BrOP resulted in effects potentiated by ATP-depletion and pro-apoptotic effects in these leukemia cells (13). In several human cancer cell lines, including the Jurkat, HeLa and U937 cell lines, glycolysis inhibition dramatically enhances apoptosis induced by Fas or tumor necrosis factor-related apoptosis-inducing ligand. This sensitization is controlled through adenosine monophosphate-activated protein kinase, which is the central energy-sensing system of the cell (14). Although this study supported that leukemia cells with high glucose metabolism were associated with chemoresistance, it remains unknown whether glycolysis-associated genes are involved in the MDR of AML.

Glycolysis is considered to be the main source of energy for tumor cells, and is much less efficient at producing energy compared with oxidative phosphorylation (15). The process of glycolysis produces only 2 mol ATP per 1 mol glucose, while oxidative phosphorylation of glucose results in $\sim 36$ mol ATP per $1 \mathrm{~mol}$ glucose. Each reaction in the glycolytic pathway is catalyzed by a specific glucose transporter (GLUT) or enzyme, such as GLUT1, hexokinase (HK), phosphofructokinase (PFK), GAPDH and enolase (ENO) $(16,17)$. Tumor cells shift their metabolism from oxidative phosphorylation towards the less efficient glycolysis, independent of the presence of oxygen. This metabolic change is associated with factors including the upregulation of glycolytic enzymes and glucose transporters, decreased expression of oxidative phosphorylation enzymes and a lower mitochondrial content (18).

The present study investigated the glycolytic activity and expression of associated molecules in drug-resistant AML cells in comparison with drug-sensitive AML cells. The increased expression of glycolytic pathway-associated genes, including hypoxia inducible factor (HIF)-1 $\alpha$, HK-II, GLUT1, and lactate dehydrogenase (LDH), and low expression of $\beta$-F1-ATPase were shown to be associated with drug resistance in AML cells. It was also observed that inhibition of glycolysis through the use of glycolytic inhibitors rendered resistant AML cells susceptible to Adriamycin (ADR). The present data suggested that glycolysis-associated genes are involved in AML drug resistance and may be promising therapeutic targets for AML therapy.

\section{Patients and methods}

Patient samples. Bone marrow and serum samples were obtained from 90 newly diagnosed and 18 relapsed patients with AML in The First Affiliated Hospital of Jishou University (Jishou, Hunan, China) between October 2010 and November 2011. Patients with AML M3 were excluded. All samples contained $\geq 80 \%$ leukemia cells. Within $24 \mathrm{~h}$ of sampling, mononuclear cells from bone marrow samples were obtained subsequent to red blood cell lysis (Wuhan Boster Biological Technology, Ltd., Wuhan, Hubei, China) of the lower fraction subsequent to density gradient centrifugation at $480 \mathrm{x}$ g. Isolated mononuclear cells were washed twice by phosphate-buffered saline (PBS; Wuhan Boster Biological Technology, Ltd.), and stored in liquid nitrogen until use. The present study was performed in accordance with the modified Declaration of Helsinki (19), and the protocol was approved by The Medicine Ethics Committee of Zhongshan City People's Hospital (Zhongshan, Guangdong, China) prior to the start of the study. Informed consent was obtained from all patients and healthy volunteers.

Cell lines and cell culture. The human AML HL-60 cell line and the ADR-resistant HL-60/ADR sub-line were obtained from the Laboratory of Hematology of Nanfang Hospital of South Medical University (Guangzhou, China). These cell lines were cultured at $37^{\circ} \mathrm{C}$ in a $5 \%$ humidified atmosphere in Gibco RPMI-1640 medium (Thermo Fisher Scientific, Inc., Waltham, MA, USA) supplemented with $10 \%$ HyClone fetal bovine serum (FBS; GE Healthcare Life Sciences, Logan, UT, USA), 100 units/ml penicillin (Guangzhou Ucando Biotechnology Co., Ltd., Guangzhou, China), $100 \mu \mathrm{g} / \mathrm{ml}$ streptomycin (Guangzhou Ucando Biotechnology Co., Ltd.) and $2 \mathrm{mM}$ glutamine (Guangzhou Ucando Biotechnology Co., Ltd.). Prior to each experiment, HL-60/ADR cells were treated with $1 \mu \mathrm{mol} / \mathrm{ml}$ ADR (Sigma-Aldrich, St. Louis, MO, USA) for 10-28 days and then cultured for 10 days without ADR exposure (20).

Glucose consumption assay. Glucose consumption was detected by the conversion of glucose to 6-phosphogluconate and reduced nicotinamide adenine dinucleotide (NADH) with the Glucose (HK) Assay kit (Sigma-Aldrich), according to the manufacturer's protocol. Briefly, $10^{6} \mathrm{HL}-60$ and HL-60/ADR cells were cultured in RPMI-1640 containing $2 \mathrm{~g} / \mathrm{l}$ glucose. Following 4 days of culture, the medium was collected by centrifugation at $715 \mathrm{x}$ g to remove the cells, and incubated at room temperature for $2 \mathrm{~h}$ with glucose assay buffer (Sigma-Aldrich), containing $1.5 \mathrm{mM}$ NAD, $1 \mathrm{mM}$ ATP, $1 \mathrm{U} / \mathrm{ml}$ hexokinase and $1 \mathrm{U} / \mathrm{ml}$ glucose-6-phosphate dehydrogenase. During this time, glucose was phosphorylated to glucose-6-phosphate. Glucose-6-phosphate was then oxidized to 6-phospho-gluconate in the presence of oxidized nicotinamide adenine dinucleotide (NAD), reducing NAD to an equimolar amount of NADH. The conversion of NAD to NADH was measured by the increase in absorbance at $340 \mathrm{~nm}$ using a spectrophotometer (UV-1800; Shimadzu, Kyoto, Japan), which was directly proportional to the glucose concentration.

RNA extraction and quantitative polymerase chain reaction ( $q P C R)$. Total RNA from cell lines and primary mononuclear cell samples were extracted using Invitrogen TRIzol reagent (Thermo Fisher Scientific, Inc.), according to the manufacturer's protocol. Subsequent to removal of the DNase I, cDNA was reverse transcribed from $1 \mu \mathrm{g}$ of total RNA in $20 \mu \mathrm{l}$ reaction volume, in accordance with the maufacturer's instructions for the PrimeScript ${ }^{\circledR}$ RT kit (Takara Biotechnology Co., Ltd., Dalian, Liaoning, China). The PCR machine was ABI7500 (Applied Biosystems; Thermo Fisher Scientific, Inc.). The sequences of the primers were as follows: HIF-1 $\alpha$ forward, 5'-ACAGCCTCACCAAACAGAGCAGG-3' and reverse, 5'-CGCTTTCTCTGAGCATTCTGCAAAGC-3'; GLUT1 
Table I. Primer sequences used in reverse transcription-qunatitative polymerase chain reaction.

\begin{tabular}{llc}
\hline Primer & \multicolumn{1}{c}{ Sequence } & Product size, bp \\
\hline$\beta$-actin & & 187 \\
Sense & 5'-TGGCACCCAGCACAATGAA-3' & \\
Antisense & 5'-CTAAGTCATAGTCCGCCTAGAAGCA-3' & 163 \\
HIF-1 $\alpha$ & & \\
Sense & 5'-ACAGCCTCACCAAACAGAGCAGG-3' & \\
Antisense & 5'-CGCTTTCTCTGAGCATTCTGCAAAGC-3' & 99 \\
GLUT1 & & 154 \\
Sense & 5'-GCGGGTTGTGCCATACTCATGACC-3' \\
Antisense & 5'-AGGCCACAAAGCCAAAGATGGCC-3' & \\
HK-II & & \\
Sense & 5'-TCTCCGCCTCGGTTTCCCAACT-3' & \\
Antisense & 5'-AAGAGGGTCTCATCAGAGAGGCGC-3' & \\
\hline
\end{tabular}

HIF-1 $\alpha$, hypoxia inducible factor-1 $\alpha$; GLUT1, glucose transporter 1; HK-II, hexokinase-II.

forward, 5'-GCGGGTTGTGCCATACTCATGACC-3' and reverse, 5'-AGGCCACAAAGCCAAAGATGGCC-3'; and $\beta$-actin forward, 5'-TGGCACCCAGCACAATGAA-3' and reverse, 5'-CTA AGTCATAGTCCGCCTAGAAGCA-3'. qPCR was performed using a SYBR Green reaction kit (Takara Biotechnology Co., Ltd.) and an Applied Biosystems PRISM 7500 real-time PCR detection system (Thermo Fisher Scientific, Inc.). The expression levels of HIF-1 $\alpha$ and GLUT1 were analyzed relative to the levels of the $\beta$-actin gene transcript. Sequences of the primers (Shanghai GenePharma Co., Ltd., Shanghai, China) were shown in Table I. The reaction mixture for each direct qPCR was performed using $10 \mu \mathrm{l}$ SYBR Premix Ex (Takara Biotechnology Co., Ltd.), $0.8 \mu \mathrm{l}(0.4 \mu \mathrm{M})$ of each primer and $2 \mu \mathrm{lDNA}$, and in a total reaction volume of $20 \mu \mathrm{l}$. The qPCR conditions consisted of pre-denaturation at $95^{\circ} \mathrm{C}$ for $30 \mathrm{sec}$, followed by 40 cycles of denaturation at $95^{\circ} \mathrm{C}$ for $3 \mathrm{sec}$ and annealing at $60^{\circ} \mathrm{C}$ for $30 \mathrm{sec}$. Three independent experiments were performed on the cells in independent cultures at 3 different times.

Western blot analysis. Cells $\left(2 \times 10^{6}\right)$ were washed twice in ice-cold PBS and then incubated for $10 \mathrm{~min}$ on ice with $300 \mu \mathrm{l}$ lysis buffer, which consisted of $1 \%$ Triton X-100, $0.1 \%$ SDS, $50 \mathrm{mM}$ Tris (pH 8.0), $150 \mathrm{mM} \mathrm{NaCl}, 1 \mathrm{mM}$ phenylmethylsulfonyl fluoride, $0.1 \mathrm{mM} \mathrm{Na} \mathrm{VO}_{4}, 0.1 \mathrm{mM}$ benzamidine, $5 \mu \mathrm{g} / \mathrm{ml}$ leupeptin and $5 \mu \mathrm{g} / \mathrm{ml}$ aprotinin (Sigma-Aldrich). Whole-cell lysates were clarified by centrifugation at $21,130 \mathrm{x}$ g for $15 \mathrm{~min}$ at $4^{\circ} \mathrm{C}$. The protein concentration was determined using the Bradford protein assay (Bio-Rad Laboratories, Hercules, CA, USA) with bovine serum albumin (Bio-Rad Laboratories) as a standard protein. In total, $30 \mu \mathrm{g}$ of protein was separated by electrophoresis on a sodium dodecyl sulfate-polyacrylamide gel (10\% gel; Sigma-Aldrich). Subsequent to electrophoresis, proteins were transferred to a nitrocellulose membrane (Millipore, Billerica, MA, USA). Following $1 \mathrm{~h}$ incubation in a blocking solution containing $5 \%$ non-fat dry milk in PBS and 0.5\% Tween-20 (Sigma-Aldrich) the membrane was blotted with the mouse monoclonal anti- $\beta$-F1-ATPase antibody (catalog no., sc-55597; dilution, 1:500; Santa Cruz Biotechnology, Inc., Dallas, TX, USA) and mouse monoclonal anti- $\beta$-actin (control) antibody (catalog no., sc-47778; dilution, 1:1,000; Santa Cruz Biotechnology, Inc.) overnight at $4^{\circ} \mathrm{C}$. Subsequent to washing, the blot was incubated with the secondary antibodies (dilution, 1:1,000; Santa Cruz Biotechnology, Inc.) for $1 \mathrm{~h}$ at room temperature. The immunoreactive bands were visualized with the enhanced chemiluminescence (ECL) reagent (Pierce Biotechnology, Inc., Rockford, IL, USA), according to the manufacturer's protocol. All the tests were repeated three times.

Enzyme-linked immunosorbent assay (ELISA). Patient serum levels of LDH were measured using Quantikine kit (R\&D Systems, Inc., Minneapolis, MN, USA), according to the manufacturer's instructions. Optical density was measured using an ELX800 ELISA reader (Bio-Tek, Winooski, VT, USA) at $492 \mathrm{~mm}$. The results were calculated from a standard curve generated by dilutions of a known amount of recombinant $\mathrm{LDH}$ protein. The LDH concentration in each sample was the average of 3 independent experiment results.

Methyl thiazolyl tetrazolium (MTT) assay. The MTT assay was performed to assess the effect of 3BrPA or 2-DG on the proliferation of AML cell lines and responsiveness to ADR. The final drug concentrations of ADR ranged between 0.25 and $5 \mu \mathrm{g} / \mathrm{ml}$ in HL-60/ADR cells and between 0.001 and $0.1 \mu \mathrm{g} / \mathrm{ml}$ in HL-60 cells. The half maximal inhibitory concentration $\left(\mathrm{IC}_{50}\right)$, which is defined as the drug concentration at which cell growth is inhibited by $50 \%$, was used as a measure of cellular drug resistance. Various concentrations of ADR $(0.25-5 \mu \mathrm{g} / \mathrm{ml}$ for HL-60/ADR cells; 0.001-0.1 $\mu \mathrm{g} / \mathrm{ml}$ for HL-60 cells) were used due to differences in ADR resistance, but corresponded with the induction of similar amounts of cell death. Inhibition of glycolysis was established by the addition of 0.25-2.00 mM 2-DG (Sigma-Aldrich) or $20 \mu \mathrm{M}$ 3BrPA (Sigma-Aldrich). HL-60 or HL-60/ADR cells were plated in 96 -well plates at a density of $5 \times 10^{4}$ cells/well for 
Table II. Clinical characteristics of patients with acute myeloid leukemia that demonstrated different sensitivities to chemotherapy.

\begin{tabular}{|c|c|c|c|c|c|c|c|}
\hline \multirow[b]{2}{*}{ Characteristics } & \multicolumn{2}{|c|}{$\mathrm{CR}$} & \multicolumn{2}{|c|}{ PR } & \multicolumn{2}{|c|}{ NR } & \multirow[b]{2}{*}{ P-value } \\
\hline & Mean & $\mathrm{n}(\%)$ & Mean & $\mathrm{n}(\%)$ & Mean & $\mathrm{n}(\%)$ & \\
\hline Total & & $64(59.3)$ & & $16(14.8)$ & & $28(25.9)$ & \\
\hline Age & 43.2 & & 44.6 & & 36.3 & & NS \\
\hline$<60$ years & & $52(81.3)$ & & $14(87.5)$ & & $26(92.9)$ & \\
\hline$\geq 60$ years & & $12(18.8)$ & & $2(12.5)$ & & $2(7.1)$ & \\
\hline Gender & & & & & & & NS \\
\hline Male & & $18(56.3)$ & & $10(62.5)$ & & $16(57.1)$ & \\
\hline Female & & $14(43.8)$ & & $6(37.5)$ & & $12(42.9)$ & \\
\hline Blasts, $\%$ & 86.9 & & 87.0 & & 89.5 & & NS \\
\hline Disease status & & & & & & & NS \\
\hline Newly diagnosed & & 58 (90.6) & & $14(87.5)$ & & $18(64.3)$ & \\
\hline Relapsed & & $6(9.4)$ & & $2(12.5)$ & & $10(35.7)$ & \\
\hline MICM & & & & & & & NS \\
\hline M2 & & $42(65.6)$ & & $14(87.5)$ & & $14(50.0)$ & \\
\hline Others (M4, M5, M7) & & $22(34.4)$ & & $2(12.5)$ & & $4(50.0)$ & \\
\hline
\end{tabular}

NS, P>0.05; MICM, morphology, immunology, cytogenetics and molecular biology; CR, complete remission; PR, partial remission; NR, no remission.

the proliferation assay. Subsequent to $48 \mathrm{~h}$, the cells were stained with $10 \mu \mathrm{l}$ sterile MTT dye ( $5 \mathrm{mg} / \mathrm{ml}$; Sigma-Aldrich) at $37^{\circ} \mathrm{C}$ for $4 \mathrm{~h}$, and the culture medium was then removed. Subsequently, $200 \mu 1$ dimethyl sulfoxide (Sigma-Aldrich) was added to the plates and thoroughly combined for $10 \mathrm{~min}$. Spectrometric absorbance at $570 \mathrm{~nm}$ was measured using the ELx800 Absorbance Microplate Reader (Bio-Tek). All groups were assessed 6 times.

Coefficient of drug interaction (CDI). The CDI is used to analyze the synergistic inhibitory effect of drug combinations. $\mathrm{CDI}$ is calculated as follows: $\mathrm{CDI}=\mathrm{AB} /(\mathrm{A} \times \mathrm{B})$, where $\mathrm{AB}$ is the ratio of absorbance of the combination groups to the control group and A or B is the ratio of the absorbance of the single agent group to the control group. Thus, a CDI of $<1$, 1 or $>1$ indicates that the drugs are synergistic, additive or antagonistic, respectively. A CDI $<0.7$ indicates that the drugs are significantly synergistic (21).

Flow cytometry. Annexin V-fluorescein isothiocyanate (FITC) apoptosis detection kit (KeyGen, Nanjing, Jiangsu, China) was used for the detection of apoptotic cells, according to the manufacturer's instructions. Briefly, $1-5 \times 10^{5} \mathrm{HL}-60$ or HL-60/ADR cells were collected and washed with PBS. From the cell suspension, cells were re-suspended in $1 \mathrm{X}$ binding buffer and then incubated with $5 \mu \mathrm{l}$ Annexin V-FITC and $5 \mu \mathrm{l}$ propidium iodide solution and incubated for $10 \mathrm{~min}$ in the dark. Fluorescence of the cells was determined immediately using flow cytometry with CellQuest 3.2 software (Becton Dickinson, San Jose, CA, USA). Staining with Annexin V and $10 \mu \mathrm{l}$ PI was performed according to the manufacturer's protocol for the Annexin V-FITC Apoptosis Detection kit
(Sigma-Aldrich). Cells in the early stages of apoptosis stain with Annexin V-FITC conjugate alone.

Statistical analysis. All statistical analysis was performed using the statistical software package SPSS 16.0 (SPSS, Inc., Chicago, IL, USA). Student's $t$-test was used to determine the significance of the differences between mean values. One-way analysis of variance was performed and post-hoc multiple comparisons were performed using the least significant difference test under homogeneity of variance, while a comparison of the means of multi-group samples was performed using Dunnett's T3 method under homogeneity of variance. The results were expressed as the mean \pm standard error, and $\mathrm{P}<0.05$ was considered to indicate a statistically significant difference.

\section{Results}

Patient characteristics. Using the chemotherapy response criteria established by the Chinese Chemotherapy Symposium of Leukemia in 1987 (22), chemotherapy response was assessed according to two induction cycles of chemotherapy. The response criteria consisted of complete remission (CR), partial remission (PR) and no remission (NR). CR was defined as $\leq 5 \%$ blasts in normocellular or hypercellular bone marrow with a normal peripheral count (granulocyte count, $>1 \times 10^{9} / 1$; platelet count, $\left.>1 \times 10^{11} / 1\right)$. PR required similar criteria, with the exception of the presence of 6-20\% marrow blasts. NR was defined as failure to achieve CR or PR. The clinical characteristics of the three patient groups are shown in Table II. In addition, 38 healthy donors acted as a negative control. 


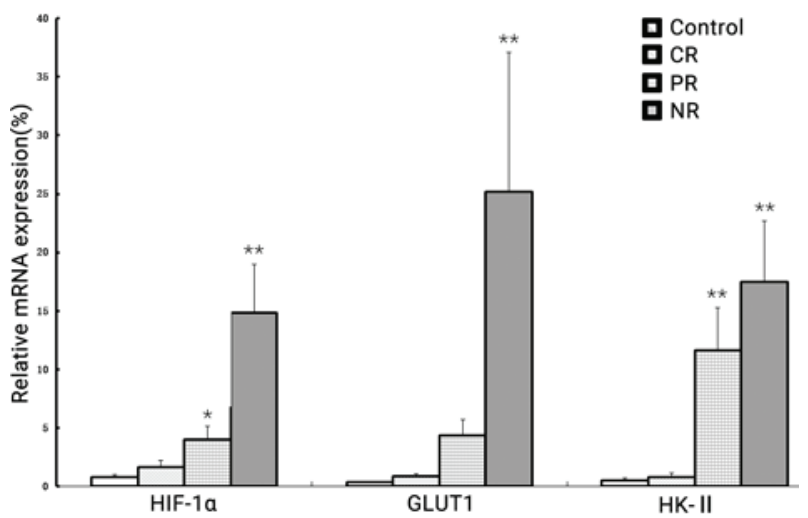

Figure 1. Expression of HIF-1 $\alpha$, GLUT1 and HK-II mRNA in blasts from AML patients with various responses to chemotherapy. The mRNA expression of these genes was detected by reverse transcription-quantitative polymerase chain reaction. The upregulation of these three genes was associated with chemoresistance in AML patients ( $\mathrm{P}<0.05$ and ${ }^{* *} \mathrm{P}<0.01$ vs. control group). HIF-1 $\alpha$, hypoxia inducible factor-1 $\alpha$; GLUT1, glucose transporter 1; HK-II, hexokinase-II; mRNA, messenger RNA; CR, complete remission; PR, partial remission; NR, no remission.

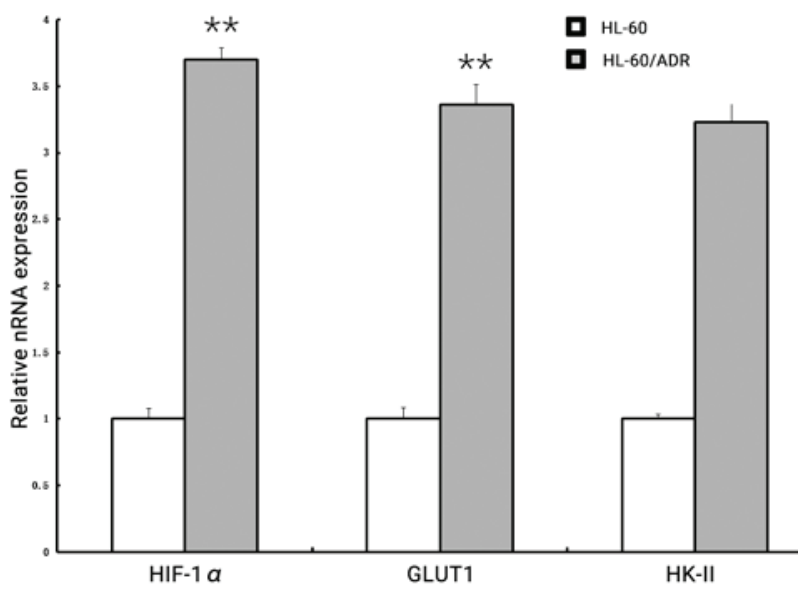

Figure 2. Expression of HIF-1 $\alpha$, GLUT1 and HK-II mRNA in AML ADR-resistant and sensitive cell lines. The expression levels of HIF-1 $\alpha$, GLUT1 and HK-II mRNA in the ADR-sensitive HL-60 and ADR-resistant HL-60/ADR cell lines were detected by reverse transcription-quantitative polymerase chain reaction. The upregulation of these three genes was associated with drug resistance in the HL-60/ADR cell line $\left({ }^{* *} \mathrm{P}<0.01\right.$ vs. HL-60 cells). ADR, Adriamycin; HIF-1 $\alpha$, hypoxia inducible factor-1 $\alpha$; GLUT1, glucose transporter 1; HK-II, hexokinase-II; mRNA, messenger RNA; AML, acute myeloid leukemia.

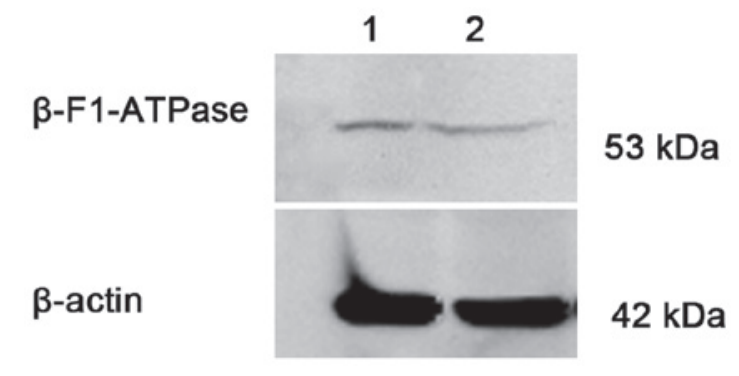

Figure 3. Expression of $\beta$-F1-ATPase in AML ADR-resistant and sensitive cell lines. The $\beta$-F1-ATPase protein expression level in the ADR-sensitive HL-60 and ADR-resistant HL-60/ADR cell lines was detected by western blot analysis. Lane 1, HL-60 cells; Lane 2, HL-60/ADR cells. ADR, Adriamycin; AML, acute myeloid leukemia; $\beta$-F1-ATPase, $\beta$ subunit of human F1-F0 adenosine triphosphate synthase.
Glycolysis in AML cell lines. The glucose consumption in ADR-resistant HL-60/ADR cells following 4 days of incubation was set as $100 \%$. The ADR-resistant AML HL-60/ADR cell line showed increased glucose consumption $(97.4 \pm 0.70 \%)$ compared with the ADR-sensitive HL-60 cell line (55.0 $\pm 3.16 \%$ ) subsequent to 4 days of culture $(\mathrm{P}<0.001)$.

HIF-1 $\alpha$, GLUT1 and HK-II messenger (m)RNA expression in primary AML cells and cell lines. As shown in Fig. 1, the transcription levels of the HIF-1 $\alpha$, GLUT1 and HK-II genes, which are involved in glucose metabolism, showed increased expression in the healthy controls, CR group, PR group and NR group $(\mathrm{P}<0.001)$. The level of HIF-1 $\alpha$ mRNA in the NR group (14.85 \pm 4.16$)$ was evidently increased compared with the healthy controls $(0.79 \pm 0.22 ; \mathrm{P}<0.001), \mathrm{CR}$ group $(1.67 \pm 0.55 ; \mathrm{P}<0.001)$ and $\mathrm{PR}$ group $(4.02 \pm 1.10 ; \mathrm{P}<0.001)$. GLUT1 mRNA expression was also markedly higher in the NR group $(25.17 \pm 11.89)$ compared with the healthy controls (0.34 $\pm 0.11 ; \mathrm{P}<0.001), \mathrm{CR}$ group $(0.83 \pm 0.24, \mathrm{P}<0.001)$ and PR group $(4.34 \pm 1.35 ; \mathrm{P}<0.001)$. Similarly, the expression of HK-II mRNA was significantly upregulated in the NR group $(17.47 \pm 5.22)$ compared with the healthy controls $(0.49 \pm 0.20$; $\mathrm{P}<0.001)$, CR group $(0.78 \pm 0.39 ; \mathrm{P}<0.001)$ and $\mathrm{PR}$ group $(11.61 \pm 3.69 ; \mathrm{P}=0.036)$.

Subsequently, the expression levels of these three genes in the AML ADR-sensitive HL-60 and ADR-resistant HL-60/ADR cell lines in vitro were compared. As shown in Fig. 2, the expression of HIF-1 $\alpha$, GLUT1 and HK-II was considerably higher in HL-60/ADR cells compared with HL-60 cells (HIF-1 $\alpha, 3.70 \pm 0.084$ vs. 1.00 0.075 , $\mathrm{P}<0.001$; GLUT1, $3.36 \pm 0.149$ vs. $1.0 \pm 0.080, \mathrm{P}<0.001$; HK-II, $3.23 \pm 0.161$ vs. $1.0 \pm 0.037, \mathrm{P}<0.001)$, respectively.

Serum LDH level in AML patients. The level of serum $\mathrm{LDH}$ was $149.90 \pm 31.66,490.63 \pm 213.94,490.75 \pm 278.35$ and $1211.57 \pm 456.99 \mathrm{U} / 1$ in the healthy control, CR, PR and NR groups, respectively. The serum LDH level was significantly increased in the NR group compared with the control $(\mathrm{P}<0.001), \mathrm{CR}(\mathrm{P}<0.001)$ and $\mathrm{PR}$ groups $(\mathrm{P}=0.003)$.

$\beta$-F1-ATPase protein expression in primary AML cells and cell lines. The protein expression level of $\beta$-F1-ATPase/ $\beta$-actin was $0.0540 \pm 0.0482$ and $0.0092 \pm 0.0042$ in the CR $(n=20)$ and NR $(n=12)$ groups, respectively. There was a significant difference between the two groups $(\mathrm{P}=0.017)$. Consistently, ADR-resistant HL-60/ADR cells showed a lower $\beta$-F1-ATPase expression compared with ADR-sensitive HL-60 cells (Fig. 3).

Effect of glycolytic inhibitor on cytotoxicity in AML cell lines. The present study investigated the response of the AML HL-60 and HL-60/ADR cell lines to ADR while inhibiting the glycolysis pathway. The cells were incubated with 2-DG or 3BrPA, which resulted in a proximal blockade of glycolysis (Fig. 4A). Following 4 days of treatment of the HL-60 and HL-60/ADR cell lines with different concentrations of 2-DG (HL-60, 0.5 mM; HL-60/ADR, $2 \mathrm{mM}$ ) or 3BrPA (HL-60, $20 \mu \mathrm{M}$; HL-60/ADR, $20 \mu \mathrm{M})$, either alone or in combination with ADR (HL-60, $0.001 \mu \mathrm{g} / \mathrm{ml}$; HL-60/ADR, $0.5 \mu \mathrm{g} / \mathrm{ml}$ ), a considerable reduction of glucose uptake was identified 

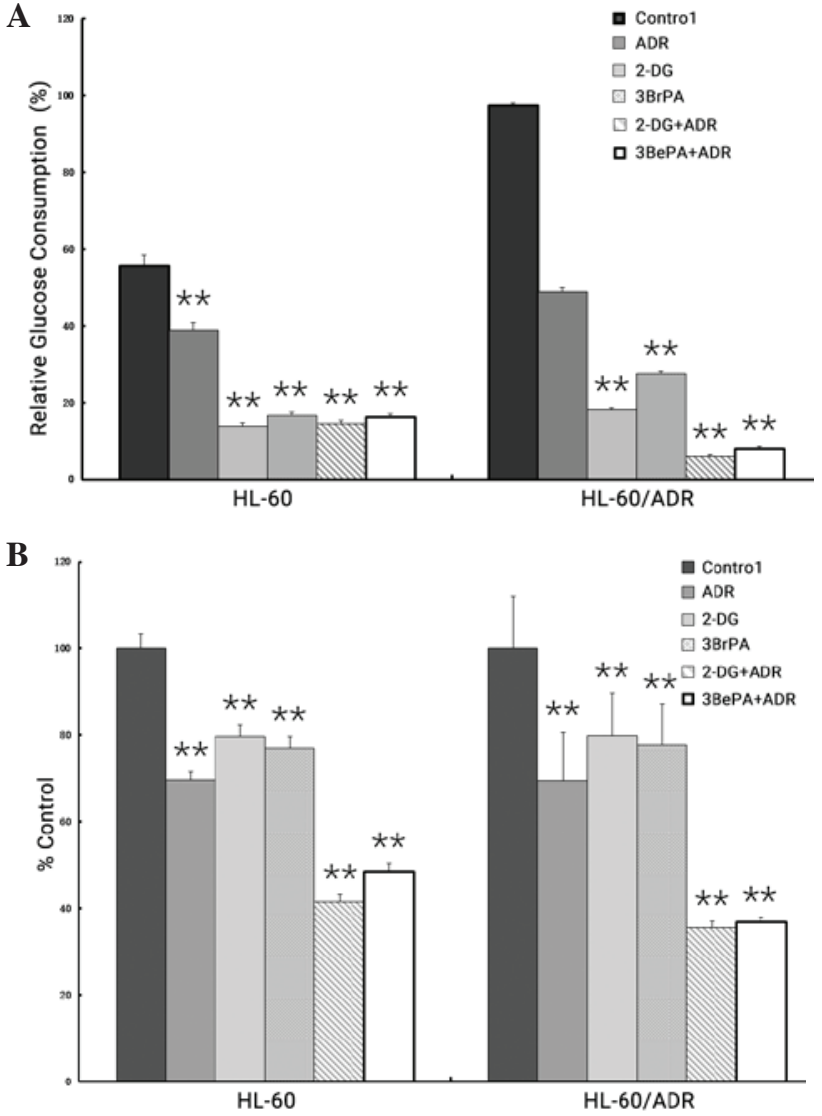

Figure 4. Effect of glycolysis inhibitors on glucose consumption and ADR-induced cytotoxicity in AML cell lines. Graphic representation of (A) relative glucose consumption or (B) in vitro ADR responsiveness in ADR-resistant and ADR-sensitive AML cell lines subsequent to 2-DG or 3BrPA treatment. Glucose consumption was calculated by measuring the conversion of glucose to 6-phosphogluconate, and glucose consumption in HL-60/ADR cells was set as 100\%. The response to ADR was measured using the methyl thiazolyl tetrazolium assay, and cell survival in non-treated cells was set as $100 \%$. Representative experiments were shown; data are expressed as the mean \pm standard deviation $(n=3)$. The combination of glycolysis inhibitor and ADR showed the synergistic effect in ADR-resistant HL-60/ADR cells $\left({ }^{* *} \mathrm{P}<0.01\right.$ vs. control group). ADR, Adriamycin; AML, acute myeloid leukemia; 2-DG, 2-deoxy-D-glucose; 3BrPA, 3-bromopyruvate.

compared with non-treated cells (Fig. 4A). The decrease in glucose consumption was not observed when cells were incubated with ADR alone.

In addition, the combination of 2-DG or 3BrPA and ADR resulted in markedly increased cytotoxicity in ADR-resistant HL-60/ADR cells (CDI <0.7), compared with treatment with glycolysis inhibitor or ADR as individual drugs (Fig. 4B). However, this synergistic effect on cell death was not observed in ADR-sensitive HL-60 cells (CDI >0.7 and <1).

Effect of glycolytic inhibitors on apoptosis in AML cell lines. A flow cytometry assay analyzed the apoptotic rates of HL-60 and HL-60/ADR cells treated with glycolytic inhibitor (2-DG or $3 \mathrm{BrPA})$ or ADR or a combination of the two agents. Following $24 \mathrm{~h}$ of treatment of the cell lines with 2-DG or 3BrPA, either alone or in combination with $\mathrm{ADR}$, the percentage of apoptotic cells in the HL-60 and HL-60/ADR cell lines showed no significant difference (Fig. 5A; P>0.05). However, treatment with 2-DG or 3BrPA in combination with ADR increased the
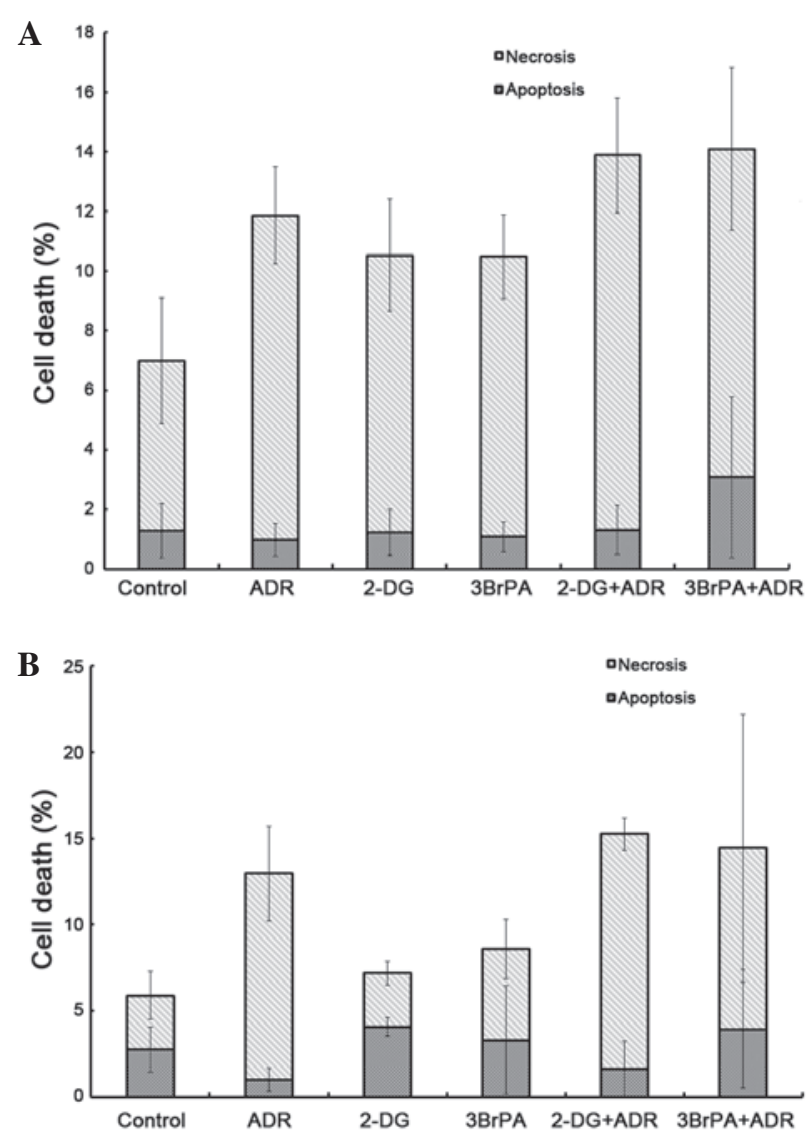

Figure 5. Effects of glycolysis inhibitiors on apopotosis in AML cell lines. ADR-induced apoptosis was measured in (A) HL-60 and (B) HL-60/ADR cells following treatment with $2-\mathrm{DG}$ or $3 \mathrm{BrPA}$ using flow cytometry. The concentrations of ADR, 2-DG and 3BrPA used to treat the ADR-resistant HL-60/ADR cells were $0.5 \mu \mathrm{g} / \mathrm{ml}, 2 \mathrm{mM}$ and $20 \mu \mathrm{M}$, respectively. ADR-sensitive HL-60 cells were incubated with $0.001 \mu \mathrm{g} / \mathrm{ml}$ ADR, $0.5 \mathrm{mM}$ 2 -DG or $20 \mu \mathrm{M} 3 \mathrm{BrPA}$. The data are expressed as the mean \pm standard deviation ( $n=3)$. ADR, Adriamycin; AML, acute myeloid leukemia; 2-DG, 2-deoxy-D-glucose; 3BrPA, 3-bromopyruvate;

necrosis of cells (Fig. 5B; $0.001 \mu \mathrm{g} / \mathrm{ml} \mathrm{ADM} \mathrm{vs.} \mathrm{control,} \mathrm{P}=0.012$; $0.5 \mathrm{mM} 2-\mathrm{DG}+0.001 \mu \mathrm{g} / \mathrm{ml} \mathrm{ADM}$ vs. control, $\mathrm{P}=0.003 ; 20 \mu \mathrm{M}$ $3 \mathrm{BrPA}+0.001 \mu \mathrm{g} / \mathrm{ml} \mathrm{ADM}$ vs. control, $\mathrm{P}=0.017)$.

\section{Discussion}

Resistance to chemotherapeutic agents is a major obstacle to the successful treatment of AML. Therefore, the development of strategies to reverse resistance to these agents may enhance the efficacy of AML treatment. Several potential mechanisms for resistance to chemotherapeutic agents have been studied in leukemia cell lines and patients with AML, but the majority of the mechanisms were not identified as sufficient causes of resistance (23). The extrusion of drugs by membrane ATP-dependent drug efflux pumps, termed ATP-binding cassette transporters, is commonly implicated in MDR. Other drug efflux pumps include P-gp, MRP, Topo II and LRP, which also contribute to chemoresistance in AML and have not yet been shown to be effective in clinical trials $(24,25)$. Previous studies have revealed that enhanced glucose uptake and aerobic glycolysis is one of the fundamental phenotypes of malignant tumors, and is important for tumor relapse and chemoresistance $(26,27)$. 
It has been reported that drug-resistant cells are characterized by defective mitochondrial ATP production, elevated aerobic glycolysis, increased absolute levels of intracellular ATP and enhanced HIF- $1 \alpha$-mediated signaling in tumor cells (27). Similar to the findings in solid tumors (28), it has been reported that high glycolytic metabolism was associated with resistance to the induction of apoptosis by chemotherapeutic agents in AML primary cells and cell lines $(11,29)$. The present results showed that the elevated glucose consumption in the ADR-resistant AML HL-60/ADR cell line compared with ADR-sensitive HL-60 cells was consistent with previous findings (11). The percentage of apoptotic cells in these cell lines showed no significant difference subsequent to treatment with a glycolysis inhibitor alone or in combination with ADR. However, 2-DG or 3BrPA in combination with ADR increased the necrosis in these cell lines $(\mathrm{P}<0.05)$. Based on these initial findings, the present study suggested that a high level of glycolysis may be associated with chemotherapy resistance in AML.

It has been shown that cancer cells, including leukemia cells, shift energy production from oxidative phosphorylation towards the less efficient glycolysis pathway (5-11,26-28). The increased glycolysis rate is due to the upregulation of several genes involved in glycolysis or glucose uptake. This upregulation in gene expression is generally considered to be due to the activation of the transcription factors c-MYC or HIF-1 $\alpha$ (12). Previous data suggests that HIF-1 $\alpha$-mediated signaling plays a central role in the process of glycolysis and chemoresistance in tumors (27). HIF-1 $\alpha$ is a transcriptional factor that upregulates the expression of specific isoforms of GLUT, HK, PFK-1, PFK-2, aldolase, GAPDH, phosphoglycerate kinase, phosphoglycerate mutase, ENO, pyruvate kinase and LDH (15). Consequently, the glycolytic flux and the levels of intermediaries are increased.

Reviewing the biochemistry of glycolysis revealed that GLUT, HK and LDH are the main controlling steps of the glycolytic flux in cells $(15,30,31)$. It appears that such modifications in these and other glycolytic steps are a component of the mechanisms involved in the increased glycolytic flux of tumor cells. The first rate-limiting step of glucose metabolism is the transport of glucose across the plasma membrane. The GLUT family of proteins is responsible for this transport, and is often found to be dysregulated or overexpressed in malignant cells (30). HK-II catalyzes the first step in the glycolytic pathway, which phosphorylates glucose into glucose-6-phosphate in the glycolytic pathway (31). LDH catalyzes the conversion of pyruvate and NADH to lactate and $\mathrm{NAD}^{+}$, which is the final step in the glycolytic pathway, and has a critical role in tumor maintenance (30). Several studies have demonstrated an association between the expression of GLUT1, HK and LDH and chemoresistance in tumors (32-34). A previous study has shown that hypoxia is closely associated with tumor resistance to anticancer drugs, and numerous factors contribute to the mechanisms of resistance (35). Direct and indirect factors of hypoxia account for drug resistance. The present study demonstrated that the expression of HIF-1 $\alpha$, GLUT1, HK-II and LDH was significantly increased in AML patients with NR compared with patients with CR and PR. Similarly, the expression of HIF-1 $\alpha$, GLUT1 and HK-II in HL-60/ADR cells was also increased compared with the expression in HL-60 cells. These findings suggested that HIF-1 $\alpha$-mediated signaling was associated with chemoresistance in AML, and the altered expression of a series of genes involved in glucose metabolism may collectively contribute to glycolysis.

In certain tumors, this glycolytic phenotype is accompanied by a loss of bioenergetic activity in mitochondria (36-38). $\beta$-F1-ATPase is the $\beta$ catalytic subunit of mitochondrial $\mathrm{H}^{+}$-ATP synthase and is the key enzyme in ATP synthesis (37). Previous studies demonstrated that downregulation of $\beta$-F1-ATPase was associated with resistance of cancer cells to anticancer therapies $(38,39)$. In the present study, it was found that the level of the $\beta$-F1-ATPase protein in ADR-resistant HL-60/ADR cells was markedly decreased compared with the level in ADR-sensitive HL-60 cells. Similarly, $\beta$-F1-ATPase expression was decreased in the NR group compared with the CR group. Overall, these results indicated the importance of the damaged mitochondrial oxidative phosphorylation regulated by $\beta$-F1-ATPase in the chemoresistance of AML.

Since drug-resistant cancer cells have increased glycolysis metabolism compared with drug-sensitive cancer and normal cells, studies have hypothesized that inhibition of glycolysis may overcome drug resistance in drug-resistant cancer cells (6-13). A previous study found that 3BrPA enhanced the cytotoxic effect of ADR, vincristine and Ara-C in drug-resistant HL-60/ADR cells, which was consistent with the aforementioned hypothesis (18). Chemopotentiating effects were investigated in ovarian carcinoma cells. The higher the resistance of a cell line to platinum, the more sensitive the cell line was to potentiation of platinum using DG, and increased glucose metabolism was shown (38). Similarly, glycolytic inhibitors, such as 2-DG, LND and 3BrPA, may reverse glucocorticoid resistance in prednisolone-resistant ALL cell lines (12). The present study showed that specifically blocking the glycolytic pathway affected ADR-resistant AML cells with high glycolytic activity, while no evident sensitizing effect was observed in cells that were already sensitive to ADR. This synergistic effect rendered ADR-resistant leukemia cells more susceptible to ADR.

It has been reported that the development of chemoresistance is associated with alterations in the apoptotic cell death pathway (40). There is also evidence to suggest that the anticancer effects of glycolytic inhibitors may be due to the activation of non-apoptotic cell death (41). Rapamycin and 2-DG markedly enhance apoptotic and non-apoptotic cell death in ovarian tumor cells (41). In the present study, the administration of 3BrPA or 2-DG was also found to enhance ADR-induced cytotoxic effects mediated by non-apoptotic cell death, in addition to apoptosis. The underlying mechanism of cell death may be a decrease in intracellular ATP levels induced by glycolytic inhibitors and ADR, which consequently induces non-apoptotic cell death. By reducing intracellular ATP levels, 2-DG may prevent ovarian cancer cells from using ATP-dependent transporters, including P-gp, which are a major cause of MDR. The notable decrease in intracellular ATP levels may render cells unable to remove cytotoxic drugs from the cell, resulting in increased intracellular concentrations of the drug and increased cell death. In the present study, treatment with 3BrPA or 2-DG in combination with ADR resulted in reduced glucose consumption. This 
may cause insufficient synthesis of ATP, which also supports the present hypothesis.

In conclusion, we the present study showed that drug resistance in AML cells was associated with increased glycolytic activity and low efficiency of oxidative phosphorylation, which was observed by the elevated expression of glycolysis-associated molecules such as HIF-1 $\alpha$, HK-II, GLUT1 and LDH. Inhibition of glycolysis may be a promising approach to reverse chemoresistance in patients with AML.

\section{Acknowledgements}

The present study was supported by grants from the Postdoctoral Science Foundation of China (grant no. 20100480834), Natural Science Foundation of Guangdong Province, China (grant no. S2012010008865) and Medical Science Foundation of Guangdong Province, China (grant no. B2010340).

\section{References}

1. Estey EH: Acute myeloid leukemia: 2013 update on risk-stratification and management. Am J Hematol 88: 318-327, 2013

2. Shipley JL and Butera JN: Acute myelogenous leukemia. Hematol 37: 649-658, 2009.

3. Shaffer BC, Gillet JP, Patel C, Baer MR, Bates SE and Gottesman MM: Drug resistance: Still a daunting challenge to the successful treatment of AML. Drug Resist Updat 15: 62-69, 2012

4. Andreeff $\mathrm{M}$ and Konopleva M: Mechanisms of drug resistance in AML. Cancer Treat Res 112: 237-262, 2002.

5. Holleman A, Cheok MH, den Boer ML, Yang W, Veerman AJ, Kazemier KM, Pei D, Cheng C, Pui CH, Relling MV, et al: Gene-expression patterns in drug-resistant acute lymphoblastic leukemia cells and response to treatment. N Engl J Med 351: 533-542, 2004.

6. Beesley AH, Firth MJ, Ford J, Weller RE, Freitas JR, Perera KU and Kees UR: Glucocorticoid resistance in T-lineage acute lymphoblastic leukaemia is associated with a proliferative metabolism. Br J Cancer 100: 1926-1936, 2009.

7. Zhao F, Mancuso A, Bui TV, Tong X, Gruber JJ, Swider CR, Sanchez PV, Lum JJ, Sayed N, Melo JV, et al: Imatinib resistance associated with BCR-ABL upregulation is dependent on HIF-1alpha-induced metabolic reprograming. Oncogene 29: 2962-2972, 2010.

8. Kluza J, Jendoubi M, Ballot C, Dammak A, Jonneaux A, Idziorek T, Joha S, Dauphin V, Malet-Martino M, Balayssac S, et al: Exploiting mitochondrial dysfunction for effective elimination of imatinib-resistant leukemic cells. PLoS One 6: e21924, 2011.

9. Kominsky DJ, Klawitter J, Brown JL, Boros LG, Melo JV, Eckhardt SG and Serkova NJ: Abnormalities in glucose uptake and metabolism in imatinib-resistant human BCR-ABL-positive cells. Clin Cancer Res 15: 3442-3450, 2009.

10. Klawitter J, Kominsky DJ, Brown JL, Klawitter J, Christians U, Leibfritz D, Melo JV, Eckhardt SG and Serkova NJ: Metabolic characteristics of imatinib resistance in chronic myeloid leukaemia cells. Br J Pharmacol 158: 588-600, 2009.

11. Herst PM, Howman RA, Neeson PJ, Berridge MV and Ritchie DS: The level of glycolytic metabolism in acute myeloid leukemia blasts at diagnosis is prognostic for clinical outcome. J Leukoc Biol 89: 51-55, 2011.

12. Hulleman E, Kazemier KM, Holleman A, VanderWeele DJ, Rudin CM, Broekhuis MJ, Evans WE, Pieters R and Den Boer ML: Inhibition of glycolysis modulates prednisolone resistance in acute lymphoblastic leukemia cells. Blood 113: 2014-2021, 2009.

13. Akers LJ, Fang W, Levy AG, Franklin AR, Huang P and Zweidler-McKay PA: Targeting glycolysis in leukemia: A novel inhibitor 3-BrOP in combination with rapamycin. Leuk Res 35: 814-820, 2011.
14. Pradelli LA, Bénéteau M, Chauvin C, Jacquin MA, Marchetti S, Muñoz-Pinedo C, Auberger P, Pende M and Ricci JE: Glycolysis inhibition sensitizes tumor cells to death receptors-induced apoptosis by AMP kinase activation leading to Mcl-1 block in translation. Oncogene 29: 1641-1652, 2010.

15. Moreno-Sánchez R, Rodríguez-Enríquez S, Saavedra E, Marín-Hernández A and Gallardo-Pérez JC: The bioenergetics of cancer: Is glycolysis the main ATP supplier in all tumor cells? Biofactors 35: 209-225, 2009.

16. Chen JQ and Russo J: Dysregulation of glucose transport, glycolysis, TCA cycle and glutaminolysis by oncogenes and tumor suppressors in cancer cells. Biochim Biophys Acta 1826: 370-384, 2012.

17. Gillies RJ, Robey I and Gatenby RA: Causes and consequences of increased glucose metabolism of cancers. J Nucl Med 49 (Suppl 2): S24-S42, 2008.

18. Xu RH, Pelicano H, Zhou Y, Carew JS, Feng L, Bhalla KN, Keating MJ and Huang P: Inhibition of glycolysis in cancer cells: A novel strategy to overcome drug resistance associated with mitochondrial respiratory defect and hypoxia. Cancer Res 65: 613-621, 2005.

19. World Medical Association: World Medical Association Declaration of Helsinki: Ethical principles for medical research involving human subjects. JAMA 310: 2191-2194, 2013.

20. Chen CY, Jia JH, Zhang MX, Meng YS, Kong DX, Pan XL and Yu XP: Proteomic analysis on multi-drug resistant cells HL-60/DOX of acute myeloblastic leukemia. Chin J Physiol 48: $115-120,2005$

21. Wang D, Wang Z, Tian B, Li X, Li S and Tian Y: Two hour exposure to sodium butyrate sensitizes bladder cancer to anticancer drugs. Int J Urol 15: 435-441, 2008.

22. Chinese Chemotherapy Symposium of Leukemia: The chemotherapy response criteria of acute leukemia Chin J Hematol 9: $183-184,1988$.

23. Reagan JL, Fast LD, Safran H, Nevola M, Winer ES, Castillo JJ, Butera JN, Quesenberry MI, Young CT and Quesenberry PJ: Cellular immunotherapy for refractory hematological malignancies. J Transl Med 11: 150, 2013.

24. de Figueiredo-Pontes LL, Pintão MC, Oliveira LC, Dalmazzo LF, Jácomo RH, Garcia AB, Falcão RP and Rego EM: Determination of P-glycoprotein, MDR-related protein 1, breast cancer resistance protein, and lung-resistance protein expression in leukemic stem cells of acute myeloid leukemia. Cytometry B Clin Cytom 74: 163-168, 2008.

25. Kaufmann SH, Karp JE, Jones RJ, Miller CB, Schneider E, Zwelling LA, Cowan K, Wendel K and Burke PJ: Topoisomerase II levels and drug sensitivity in adult acute myelogenous leukemia. Blood 83: 517-530, 1994.

26. Suh DH, Kim MK, No JH, Chung HH and Song YS: Metabolic approaches to overcoming chemoresistance in ovarian cancer. Ann N Y Acad Sci 1229: 53-60, 2011.

27. Zhou Y, Tozzi F, Chen J, Fan F, Xia L, Wang J, Gao G, Zhang A, $\mathrm{Xia} \mathrm{X}$, Brasher $\mathrm{H}$, et al: Intracellular ATP levels are a pivotal determinant of chemoresistance in colon cancer cells. Cancer Res 72: 304-314, 2012.

28. Gatenby RA and Gillies RJ: Why do cancers have high aerobic glycolysis? Nat Rev Cancer 4: 891-899, 2004.

29. Herst PM, Hesketh EL, Ritchie DS and Berridge MV: Glycolytic metabolism confers resistance to combined all-trans retinoic acid and arsenic trioxide-induced apoptosis in HL60rho0 cells. Leuk Res 32: 327-333, 2008.

30. Zhao Y, Butler EB and Tan M: Targeting cellular metabolism to improve cancer therapeutics. Cell Death Dis 4: e532, 2013.

31. Pedersen PL, Mathupala S, Rempel A, Geschwind JF and Ko YH: Mitochondrial bound type II hexokinase: A key player in the growth and survival of many cancers and an ideal prospect for therapeutic intervention. Biochim Biophys Acta 1555: 14-20, 2002.

32. Ulanovskaya OA, Cui J, Kron SJ and Kozmin SA: A pairwise chemical genetic screen identifies new inhibitors of glucose transport. Chem Biol 18: 222-230, 2011.

33. Wolf A, Agnihotri S, Micallef J, Mukherjee J, Sabha N, Cairns R, Hawkins C and Guha A: Hexokinase 2 is a key mediator of aerobic glycolysis and promotes tumor growth in human glioblastoma multiforme. J Exp Med 208: 313-326, 2011.

34. Teng CL, Young JH, Hsu SL, Chou G, Kuo IT, Yu CY and Hwang GY: Lactate dehydrogenase, not vascular endothelial growth factor or basic fibroblast growth factor, positively correlates to bone marrow vascularity in acute myeloid leukemia. J Chin Med Assoc 69: 534-537, 2006. 
35. Shannon AM, Bouchier-Hayes DJ, Condron CM and Toomey D: Tumour hypoxia, chemotherapeutic resistance and hypoxia-related therapies Cancer Treat Rev 29: 297-307, 2003.

36. López-Ríos F, Sánchez-Aragó M, García-García E, Ortega AD Berrendero JR, Pozo-Rodríguez F, López-Encuentra A, Ballestín C and Cuezva JM: Loss of the mitochondrial bioenergetic capacity underlies the glucose avidity of carcinomas. Cancer Res 67: 9013-9017, 2007.

37. Sánchez-Aragó M and Cuezva JM: The bioenergetic signature of isogenic colon cancer cells predicts the cell death response to treatment with 3-bromopyruvate, iodoacetate or 5-fluorouracil. J Transl Med 9: 19, 2011.
38. Hernlund E, Hjerpe E, Avall-Lundqvist E and Shoshan M: Ovarian carcinoma cells with low levels of beta-F1-ATPase are sensitive to combined platinum and 2-deoxy-D-glucose treatment. Mol Cancer Ther 8: 1916-1923, 2009.

39. Shin YK, Yoo BC, Chang HJ, Jeon E, Hong SH, Jung MS, Lim SJ and Park JG: Down-regulation of mitochondrial F1F0-ATP synthase in human colon cancer cells with induced 5-fluorouracil resistance. Cancer Res 65: 3162-3170, 2005.

40. Hajra KM and Liu JR: Aoptosome dysfunction in human cancer. Apoptosis 9: 691-704, 2004.

41. Loar P, Wahl H, Kshirsagar M, Gossner G, Griffith K and Liu JR Inhibition of glycolysis enhances cisplatin-induced apoptosis in ovarian cancer cells. Am J Obstet Gynecol 202: 371. e1-e8, 2010. 